\title{
Inhibition of VEGF receptors significantly impairs mammary cancer growth in C3(1)/Tag transgenic mice through antiangiogenic and non-antiangiogenic mechanisms
}

\author{
Jung-Im Huh, Alfonso Calvo, Jeffrey Stafford, Mui Cheung, Rakesh Kumar, Deborah Philp,
} Hynda K Kleinman and Jeffrey E Green

Oncogene (2005) 24, 4164. doi:10.1038/sj.onc.1208767

Correction to: Oncogene (2005) 24, 790-800.

doi:10.1038/sj.onc. 1208221

Published online 13 December 2004

Since publication of the above manuscript, the authors have identified three errors in this paper. These are detailed here.

The correct affiliation for Jeffrey Stafford, Mui Cheung and Rakesh Kumar is 'GlaxoSmithKline,
Research Triangle Park, NC, USA' and the correct affiliation for Deborah Philp and Hynda K Kleinman is 'Cell Biology Section, National Institute of Dental and Craniofacial Research, National Institutes of Health, Bethesda, MD, USA'.

In the second sentence of the first paragraph of the Results section, the concentration '156-' should be omitted.

The first sentence of the fourth paragraph of the same page should read 'Our study demonstrates that GW654652 induces apoptosis in both HUVECs and M6 cells following a cell growth arrest...'.

\section{Phosphorylation of $\mathrm{MdmX}$ by $\mathrm{CDK} 2 / \mathrm{Cdc}^{\mathrm{p} 34}$ is required for nuclear export of Mdm2}

\author{
Bertha Elias, Aaron Laine and Ze'ev Ronai
}

Oncogene (2005) 24, 4164. doi:10.1038/sj.onc.1208768

Correction to: Oncogene (2005) 24, 2574-2579.

doi: $10.1038 /$ sj.onc. 1208488

Published online 14 February 2005

Since publication of the above manuscript, the authors have identified an error in the shared affiliation. The correct affiliation should be: 'Department of Oncological Sciences, Cancer Center, Mount Sinai School of Medicine, One Gustave L. Levy Place, Box 1130, New York, NY 10029, USA'.

The protein CDK $1 / \mathrm{Cdc}^{\mathrm{p} 34}$ was also referred incorrectly throughout the text as $\mathrm{CDK} 2 / \mathrm{Cdc}^{\mathrm{p} 34}$. The authors would like to apologize for any inconvenience or confusion caused by this error. 